Revue d'histoire de l'Amérique française

BEYUE D.HISTOIRE DE L'AMÉRIQUE FRANÇAISE

\title{
ANDRÈS, Bernard et Marc André BERNIER, dir., Portrait des arts, des lettres et de l'éloquence au Québec (1760-1840) (Sainte-Foy, Les Presses de l'Université Laval, 2002), 509 p.
}

\section{Fernande Roy}

Volume 57, numéro 3, hiver 2004

URI : https://id.erudit.org/iderudit/009604ar

DOI : https://doi.org/10.7202/009604ar

Aller au sommaire du numéro

Éditeur(s)

Institut d'histoire de l'Amérique française

ISSN

0035-2357 (imprimé)

1492-1383 (numérique)

Découvrir la revue

Citer cette note

Roy, F. (2004). ANDRÈS, Bernard et Marc André BERNIER, dir., Portrait des arts, des lettres et de l'éloquence au Québec (1760-1840) (Sainte-Foy, Les Presses de l'Université Laval, 2002), 509 p. Revue d'histoire de l'Amérique française, 57(3), 444-445. https://doi.org/10.7202/009604ar d'utilisation que vous pouvez consulter en ligne. 
Enfin, les historiens de Montréal et de l'histoire sociale québécoise apprécieront l'ouvrage pour la qualité de son analyse et pour sa magnifique iconographie. Cependant, ceux qui connaissent mal les environs du boulevard Saint-Laurent auront de la difficulté à saisir son organisation spatiale et son environnement urbain en raison de l'insuffisance de cartes, et ce, même si l'ouvrage s'adresse au grand public.

JULIE DUCHESNE Département d'histoire Université du Québec à Montréal

ANDRÈS, Bernard et Marc André BERNIER, dir., Portrait des arts, des lettres et de l'éloquence au Québec (I 760-1 840) (Sainte-Foy, Les Presses de I'Université Laval, 2002), 509 p.

Ce livre volumineux représente les actes d'un colloque tenu au Château Ramezay en avril 2000. Comme l'exposition «Images d'un changement de siècle " s'y trouvait en même temps, on a eu l'heureuse idée d'agrémenter l'ouvrage d'une trentaine d'illustrations. Bernard Andrès et Marc André Bernier signent une substantielle introduction, sans doute un des plus stimulants textes du recueil. Au-delà de l'habituel panorama, c'est une interprétation d'ensemble qu'ils offrent aux lecteurs. Entre deux événements majeurs, voire deux traumatismes s'insèrent deux générations littéraires, celle des lendemains de Conquête et celle des Patriotes, qui inventent une culture lettrée. Le parti pris interprétatif s'efforce de relier cette fondation culturelle à la question identitaire. On souligne le double aspect de la culture, marquée à la fois par l'héritage classique de la culture européenne et par la conscience d'appartenir au Nouveau Monde. Pour la période concernée, Andrès et Bernier soulignent la pluralité des voix, "avant que ne triomphent cléricalisme et ultramontanisme dans la seconde moitié du XIX ${ }^{\mathrm{e}}$ siècle et au début du $\mathrm{xx}^{\mathrm{e}}$ siècle» (p. 15). De la part de chercheurs qui scrutent minutieusement leurs textes, cette extrapolation sur une période qu'ils n'ont pas étudiée étonne et il ne faut peut-être pas trop s'en soucier. Avant 1840, les champs littéraires et artistiques commencent à se constituer et personne ne s'attend à y trouver des «œuvres »; l'intérêt est plutôt de voir s'élaborer des stratégies discursives, des pratiques de lecture, des arts picturaux qui «bourgeonnent». Les premiers écrivains participent à tous les débats de société - liberté d'expression, langue française, constitution, projet d'université, etc. - contribuant ainsi à la fabrication d'un espace public au sens d'Habermas. Si cette introduction aide à voir le portrait des lettres et de l'éloquence, elle néglige quelque peu celui des arts. 
Les auteurs des 28 communications sont très majoritairement des littéraires, accompagnés de quelques historiens de l'art et de quelques historiens. Une grande partie des textes s'intéressent, sous un angle ou sous un autre, à un individu. Sans surprise, la qualité est très inégale et ce recueil fait la démonstration qu'on ne devrait jamais publier toutes les communications d'un colloque. Parmi les meilleurs, les textes de René Beaudoin, de Julie Roy, de Pierre Lespérance, de Lucie Robert et de Marc André Bernier.

Une imposante bibliographie complète l'ouvrage.

FERNANDE ROY

Département d'histoire

Université du Québec à Montréal

LA FONTAINE, Louis-Hippolyte, Correspondance générale, Tome I : Les ficelles du pouvoir : Correspondance entre Louis-Hippolyte La Fontaine et Robert Baldwin, I840-I854 (Montréal, Les Éditions Varia, coll. «Documents et Biographies», 2002), 227 p.

Comment ne pas féliciter cette jeune maison d'édition, fondée en 1996, d'avoir pris l'initiative de publier la "correspondance générale» d'un aussi important personnage politique qui joua un rôle de tout premier plan sous le régime de l'Union des deux Canadas? Il est prévu d'y consacrer trois tomes, dont le premier porte exclusivement sur l'échange épistolaire avec son grand et fidèle allié réformiste du Haut-Canada. Le combat que Louis-Hippolyte La Fontaine et Robert Baldwin menèrent pour promouvoir la cause d'un gouvernement colonial «responsable» scella une durable amitié entre eux.

Ce premier tome comporte une présentation analytique condensée et équilibrée de l'historien Éric Bédard qui précise bien la portée du contenu et l'intérêt historique que revêt l'échange de correspondance «entre les deux piliers du premier gouvernement de l'Union canadienne». Malheureusement, le travail éditorial laisse à désirer quant à la fiabilité même de la version française qui nous est présentée. L'éditeur responsable, Georges Aubin, n’a pas jugé devoir soumettre au contrôle d'une expertise professionnelle la traduction française de Nicole Panet-Raymond Roy et de Suzanne Manseau de Grandmont, «léguée à la Société historique de Montréal». Ce très productif compilateur de textes avoue candidement avoir assumé lui-même cette révision et «corrigé ici et là un certain nombre d'erreurs de lecture et des tournures incorrectes» (p. 19).

La fiabilité d'une traduction de documents historiques exige bien davantage que d'être conforme à des règles grammaticales ou stylistiques. Il importe surtout de posséder une bonne connaissance du contexte 